SOI: 1.1 /TAS DOI: $10.15863 /$ TAS

International Scientific Journal Theoretical \& Applied Science

p-ISSN: 2308-4944 (print) $\quad$ e-ISSN: 2409-0085 (online)

Year: $2015 \quad$ Issue: $07 \quad$ Volume: 27

Published: $30.07 .2015 \quad \underline{\text { http://T-Science.org }}$

SECTION 6. Metallurgy and energy.
Arman Arstangalievich Kabdushev

Master of oil and gas

Senior lecturer of the Department of «Oil and gas

engineering»

M.Kh. Dulaty Taraz State University, Kazakhstan

Arman-kz@mail.ru

Aizhan Zharylkasynovna Betzhanova Master of oil and gas

Senior lecturer of the Department of «Oil and gas engineering»

M.Kh. Dulaty Taraz State University, Kazakhstan

\title{
THE PROBLEM OF COMPLICATIONS IN THE EXTRACTION OF OIL IN THE KARAZHANBAS OILFIELD
}

Abstract: The article presents the problems and complications that are encountered in the production of highwax oil Karazhanbas and the results of the works on prevention and elimination of these complications in the field.

Key words: Heavy oil, sand, water cut wells, Karazhanbas.

Language: Russian

Citation: Kabdushev AA, Betzhanova AZ (2015) THE PROBLEM OF COMPLICATIONS IN THE EXTRACTION OF OIL IN THE KARAZHANBAS OILFIELD. ISJ Theoretical \& Applied Science 07 (27): 166168.

Soi: http://s-o-i.org/1.1/TAS-07-27-29 Doi: crossef http://dx.doi.org/10.15863/TAS.2015.07.27.29

\section{ПРОБЛЕМА ОСЛОЖНЕНИЙ ПРИ ДОБЫЧЕ НЕФТИ НА МЕСТОРОЖДЕНИИ КАРАЖАНБАС}

Аннотация: В статье приведены проблемы и осложнения, которые встречаются при добыче высокопарафинистой нефти Каражанбас и результаты проведенных работ по профилактике и ликвидации этих осложнении на месторождении.

Ключевые слова: Высоковязкая нефть, пескопроявления, обводненность скважин, Каражанбас.

Крупные месторождения высоковязких нефтей находятся в Канаде, США, Венесуэле, а в Казахстане высоковязкими месторождениями считаются в основном месторождение Северные Бузачи, Каламкас, Каражанбас, Жетыбай и.т.д.

Нефти залежи тяжелые ( $\mathrm{p}=0,938-0,944$ кг/м ${ }^{3}$ ), высокосмолистые (до 24\%), сернистые (до $2 \%$ ). Выход светлых фракций около $30 \%$, выкипающих при температуре до 300-350 С. Нефть содержит пятиокись ванадия 250-300г/т. Вязкость пластовой нефти - от 160 до 500 МПас. [1].

Связи с тем что месторождения Казахстана имеют сложность разработки наиболее значительные из них практически были лишены первого и второго этапов разработки.

Разработка месторождения осуществлялось с применением внутрипластового влажное горение (ВВГ) до 1996 года, а паротепловое воздействие (ПТВ) осуществляется по настоящее время [2,3].

Для поддержания пластового давления на месторождении ведется закачка холодной и горячей воды.

В настоящее время на месторождении
Каражанбас проводятся опытно-промышленные работы по внедрению двухосновных технологий повышения нефтеотдачи пластов термическими методами - внутрипластового влажного горения и паротеплового воздействия на пласт [4].

Оба метода в условиях месторождения Каражанбас применяются с хорошей технологической и экономической эффективностью.

Но параллельно и имеются проблемы с осадкой асфальто - смолистых веществ в добывающих скважинах.

Основными осложнениями при эксплуатации скважин на месторождении Каражанбас являются: обводнение и пескопроявления.

Снижение доли высокообводненных скважин в 1990-1992 гг. связано с выбытием этих скважин из действующего фонда.

Для борьбы с обводнённостью продукции на месторождении Каражанбас применялись следующие методы: закачка ВУС; закачка ВУС по методике КазНИПИнефть; закачка гипана; закачка Асарской высокопарафинистой нефти; закачка нефтесернокислой смеси; Закачка 
этилсиликатной смолы; закачка полимернощелочного раствора; цементаж.

Закачка изоляционных составов проводилась по методикам и рекомендациям ВНИПИтермнефть [2,3].

В результате проведенного анализа можно сделать следующее обобщение:

1. Проведенные работы показали низкий и непродолжительный эффект.

2. Такие виды работ, как закачка полиакриламида с хромкалиевыми квасцами и закачка нефтесернокислотной смеси оказались безрезультатными.

3. Наибольшее распространение среди всех видов проведенных работ оказались наиболее успешными.

Невысокая эффективность работ по нашему мнению объясняется следующими причинами:

1. Низким качеством закачиваемой композиции: недостаточное количество реагентов для образования геля.

2. Большой объём продавочной жидкости, которое отрицательно сказывается на качестве ВУСа и снижает время его действия.

3. Отклонение от норм технологии закачки и отсутствие контроля за её соблюдением.

4. Низкий эффект от закачки гипана объясняется тем, что взаимодействие его с жидкостью, находящейся в пласте, происходит только на их контактах, зона образовавшейся смеси незначительна, поэтому в реакцию вступает только часть объёмов закачиваемых реагентов. Кроме того, при температуре более $70^{\circ}$ резко снижаются вязкость водных растворов гипана и адсорбируемость, вследствие улучшения при высоких температурах растворяющей способности воды и начала разрушения водородных связей. Несмотря на то, что при этих температурах скорость структирования растёр, образующийся при этом гель имеет низкие структурно-механические свойства. Это обстоятельство ограничивает применение гипана в высокотемпературных скважинах.

Влияние песчанных пробок на производительность скважин очень велико, так, например, если даже проницаемость песчаной пробки будет на порядок выше проницаемости пласта, следует ожидать снижение дебита скважины в 5-10 раз, по отношению к дебиту не засоренной скважины $[3,5,6]$.

Особую актуальность проблема пескопроявлений приобрела с развитием термических методов добычи высоковязких нефтей. Это связано с тем, что тепловое воздействие на залежь снижает вязкость нефти, и повышает ее текучесть. Однако, в этом случае рыхлые коллекторы теряют цементирующее связующее - вязкую нефть.
Кроме того, одной из основных причин выноса песка и разрушения породы пласта является то, что минимальные депрессии на пласт при вводе скважин в эксплуатацию составляет в абсолютном выражении 1,0-1,5 Мпа, хотя допустимые с точки зрения предовращащения выноса песка находятся в пределах 0,2-0,4 Мпа. Это, как уже отмечалось, является основной причиной быстрого разрушения материала пород и интенсивного выноса песка, содержание которого в продукции скважин может достигать $3-10 \%[7,8,9]$.

Борьба с выносом песка на месторождении велась в двух направлениях [10]:

- установкой забойных вставных противопесочных фильтров;

$$
\text { - крепление призабойной }
$$

зоны химическим способом.

Продукция скважин и рабочая среда

месторождения Каражанбас, содержат

коррозионно-агрессивные компоненты:

Углекислый газ, сера, ионы хлора, сульфат ионы, механические примеси и др. Высокая коррозионная активность соответствует пороговым значениям хлор иона свыше 50 мг/л в интервале значений $\mathrm{pH} 4,5-8,5$.По содержанию хлоридов, серы и механические примесей нефть является потенциально агрессивной. В начальный период эксплуатации месторождения из-за незначительной обводненности продукции коррозионные процессы не проявляются. В процессе дальнейшей эксплуатации месторождения с увеличением обводненности продукции увеличивается коррозионная активность добываемой жидкости.

Для получения определенных выводов определенных выводов по эффективности технологии выработки запасов нефти следует продолжить их испытание с усилением контроля за достоверностью получаемой информации. Все нагнетательные скважины после периода закачки пара опробовать на приток нефти, что позволит получить как дополнительную нефть, так и увеличить охват процессом вытеснения за счет интенсивного дренирования пластов; необходимо осуществить регулирование объемов закачки вытесняющего агента в соответствии с эффективной нефтенасыщенной мощностью эксплуатируемого объекта в той или иной нагнетательной скважине (прямая пропорциональность объемов закачки и эффективной нефтенасыщенной мощности. Необходимо расширить область воздействия на пласты повышенным давлением закачки горячей воды, с целью обеспечения пластового давления и фонтанирования обводненных эксплуатационных скважин. Продолжить применение различных загустителей вытесняющего агента для выравнивания и 


\begin{tabular}{|c|c|c|c|c|c|c|}
\hline Impact Factor: & $\begin{array}{l}\text { ISRA (India) } \\
\text { ISI (Dubai, UAF } \\
\text { GIF (Australia) } \\
\text { JIF }\end{array}$ & $\begin{array}{l}=1.344 \\
=\mathbf{0 . 8 2 9} \\
=\mathbf{0 . 3 5 6} \\
=1.500\end{array}$ & $\begin{array}{l}\text { SIS (USA) } \\
\text { PИHЦ (Russia) } \\
\text { ESJI (KZ) } \\
\text { SJIF (Morocco) }\end{array}$ & $\begin{array}{l}=0.912 \\
=0.179 \\
=1.042 \\
=2.031\end{array}$ & ICV (Poland) & $=6.630$ \\
\hline
\end{tabular}

регулирования фронта вытеснения.

\section{References:}

1. Minnibaeva SB, Radaykina ZV (2000) Dopolnenie $\mathrm{k}$ tekhnologicheskoy skheme razrabotki mestorozhdeniya Karazhanbas s primeneniem termicheskikh metodov. Otchet po dogovoru 34/99. - Aktau: Fond «NIPImunaygaz», 2000.

2. Khanin AA (1969) Oil and gas reservoir rocks and their study. - Moscow: Nedra, pp. 366.

3. Budnikov VF, Solov'eva VN (1993) Kompleksnyy analiz razrabotki mestorozhdeniya Karazhanbas. Otchet po dogovoru R-14.92-93 gg. - Aktau: Fond «Karazhanbasmunaygaz».

4. Minnibaeva SB, Chebotarev SY (2000) Analiz razrabotki mestorozhdeniya Karazhanbas. Otchet po dogovoru 34/99. - Aktau: Fond «NIPImunaygaz».

5. Aschenbrenner VS, Chilingar GV, Teodorovich GI (1960) Method for determining permeability from pore-space characteristics of carbonate rocks.Bull. Am. Assoc. of Petroleum Geologists, vol. 44, pp. 1421-1444.
6. Barenblatt GI, Zheltov YP (2015) Fundamental equation of filtration of homogeneous liquids in fissured rocks. Academy of Sciences, USSR, pp. 522-526.

7. Lysenko VD (1987) Proektirovanie razrabotki neftyanykh mestorozhdeniy. - Moscow, 1987.

8. (1998) Proekt opytno-promyshlennoy ekspluatatsii vostochnogo uchastka mestorozhdeniya Karazhanbas. - Aktau: Fond «NIPImunaygaz», 1998.

9. T.D. VAN GOLF-RACHT (1982) Fundamentals of fractured reservoir engineering. Elsevier scientific publishing company. Amsterdam - Oxford - New York, 1982.

10. Stearns DW, Friedman M (1972) Reservoirs in fractured rock in stratigraphic oil and gas fields classification, exploration methods and case histories. Am. Assoc. Petroleum Geologists. Mem. 16, pp. 82-106. 